\title{
FAMILIAL ANKYLOSING VERTEBRAL HYPEROSTOSIS WITH TYLOSIS
}

\author{
BY \\ ANN BEARDWELL \\ From the Department of Physical Medicine and Rheumatology, Royal Free Hospital, London
}

Forestier and Rotès-Querol (1950) described a spinal condition characterized by ossification of the paraspinal ligaments and the formation of giant osteophytes. This condition had in fact been known to pathologists in the 19th century who had called it the sugar-icing spine. Forestier and RotèsQuerol observed these spinal changes in the elderly and for this reason called the condition "senile ankylosing hyperostosis". Since this original description, further cases have been reported (Ott, 1953; Sharp, 1957). The condition has been described in younger patients and an association with diabetes mellitus noted (Boulet, Serre, and Mirouze, 1954; Boulet and Mirouze, 1954; Ott, Schwenkenbecher, and Iser, 1963; Ott, Perkovac, and Regehr, 1967; Julkunen, 1967). A familial incidence of this condition has not previously been observed.

A Greek Cypriot family is described, many members of whom have well-developed changes of ankylosing vertebral hyperostosis (AVH) by the third decade. In addition many members of this family have tylosis (punctate hyperkeratosis).

\section{Clinical Material}

A Greek-Cypriot housewife aged 36 was first seen in the Orthopaedic Department of the Royal Free Hospital, London, complaining of lower thoracic backache of several months' duration. Because of the $x$-ray appearances, she was referred to the Department of Physical Medicine and Rheumatology in August, 1966, as a case of atypical ankylosing spondylitis. At that time she was grossly obese (weight $267 \mathrm{lb}$.; height $5 \mathrm{ft}$ ). Movements of the lower dorsal and lumbar spine were moderately limited and painful. There were signs of osteoarthrosis of both knees but no other evidence of a peripheral arthropathy. She also had punctate hyperkeratosis (tylosis) on both feet (Fig. 1, opposite) and stated that many members of her family had this condition. There were no signs of psoriasis.
Examination. $-X$ rays of the patient's spine showed ossification of paraspinal distribution, particularly in the lower thoracic region (Figs 2 and 3, opposite). There was also some osteophytosis and marginal sclerosis of the sacroiliac joints. Laboratory investigations all gave normal results, and in particular no abnormalities of calcium or carbohydrate metabolism were demonstrated. There was no evidence of an inflammatory arthritis.

Family.-The patient was accompanied by her equally fat 39-year-old sister (weight 231 lb., height $5 \mathrm{ft} 3$ in.), who also had tylosis. Because of this, although she had no back symptoms, she was asked to have her spine $x$-rayed, and the findings were very similar to those in the first sister.

Full investigation of the family was then carried out (Fig. 4, opposite).

The parents are dead. The father (II, 3) and many of his family are said to have had tylosis, but nothing is known about his spine. There were three brothers; the eldest (III, 6) died in Cyprus at the age of 41 of a heart attack, but the other two are in London and have been seen. Both are symptom-free but have paravertebral ossification and osteophytosis and both have tylosis (Fig. 5, overleaf). The youngest brother (III, 10) also has mild psoriasis, but no sign of psoriatic arthropathy.

The five siblings between them have twenty children and three grandchildren. All are in London and all have been seen, although one boy aged 18 (IV, 27) refused examination. The ages of the children (IV, $15-24)$ range between 4 and 23 years. The grandchildren $(\mathrm{V}, 3-5)$ are all under 2 years. Five of the children have mild tylosis. None have any other clinical abnormalities. There are nine children over 15 and eight of these have had their spines $x$-rayed. The eldest girl (IV, 15) aged 23 (weight $210 \mathrm{lb}$., height $5 \mathrm{ft} 1 \mathrm{in}$.) has early changes in the thoracic spine and sclerosis of both sacroiliac joints. One boy aged 18 (IV, 22) has slight changes in the thoracic region which may be significant (Fig. 6, overleaf); he is not overweight. Of the twenty children, eight are overweight for their height and age, but only one is frankly obese (height $5 \mathrm{ft} 1$ in., weight 216 lb.). 


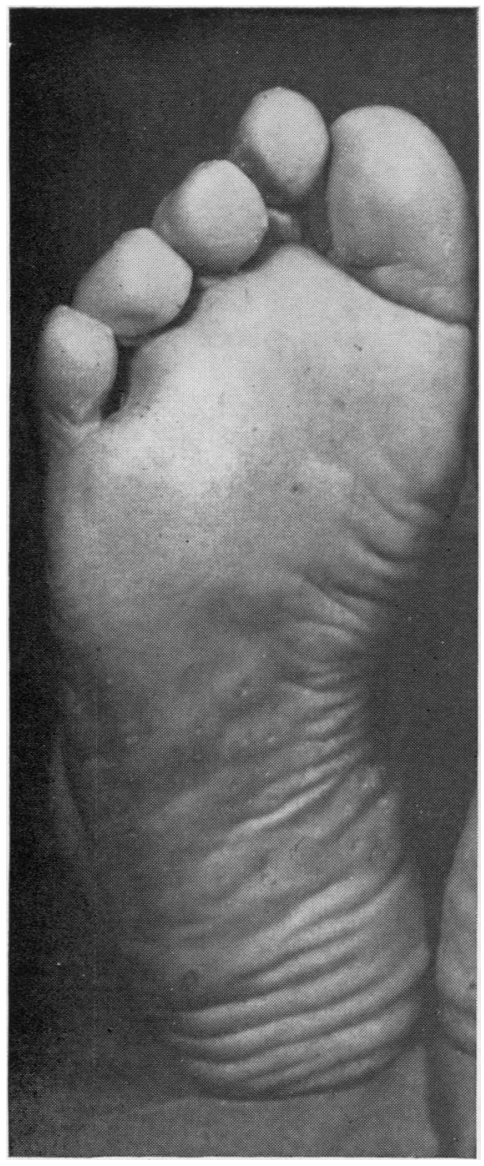

Fig. 1.-Hyperkeratosis punctata plantaris (tylosis)-foot of proband (III, 9).

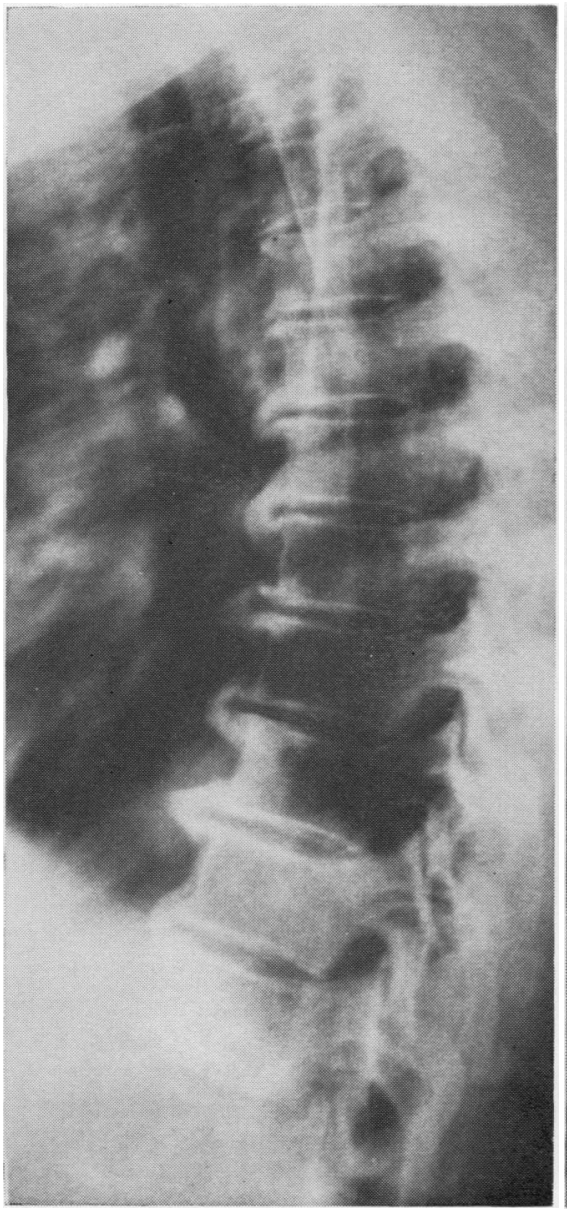

Fig. 2.-Thoracic spine, lateral view, showing advanced ligamentous ossification (Patient III, 9).

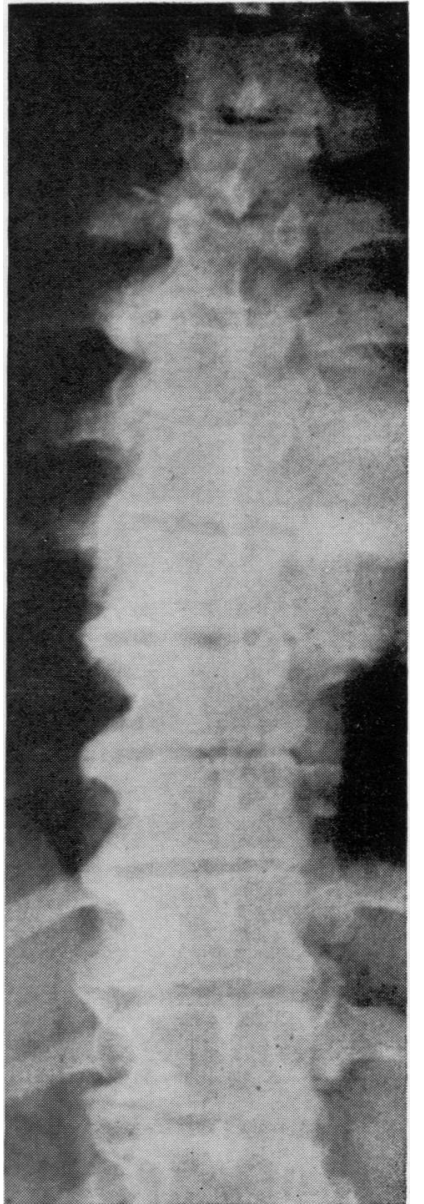

Fig. 3.-Thoracic spine, posteroanterior view (Patient III, 9)

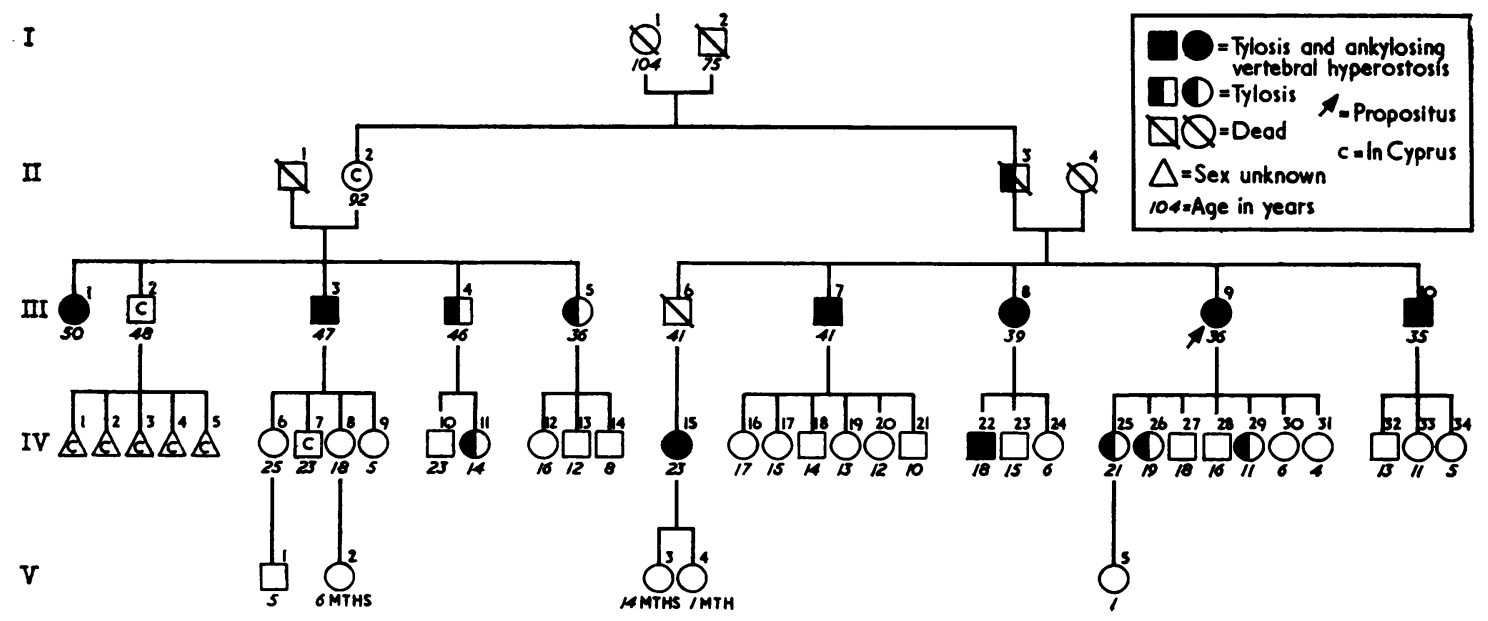

Fig. 4.-Family tree. 


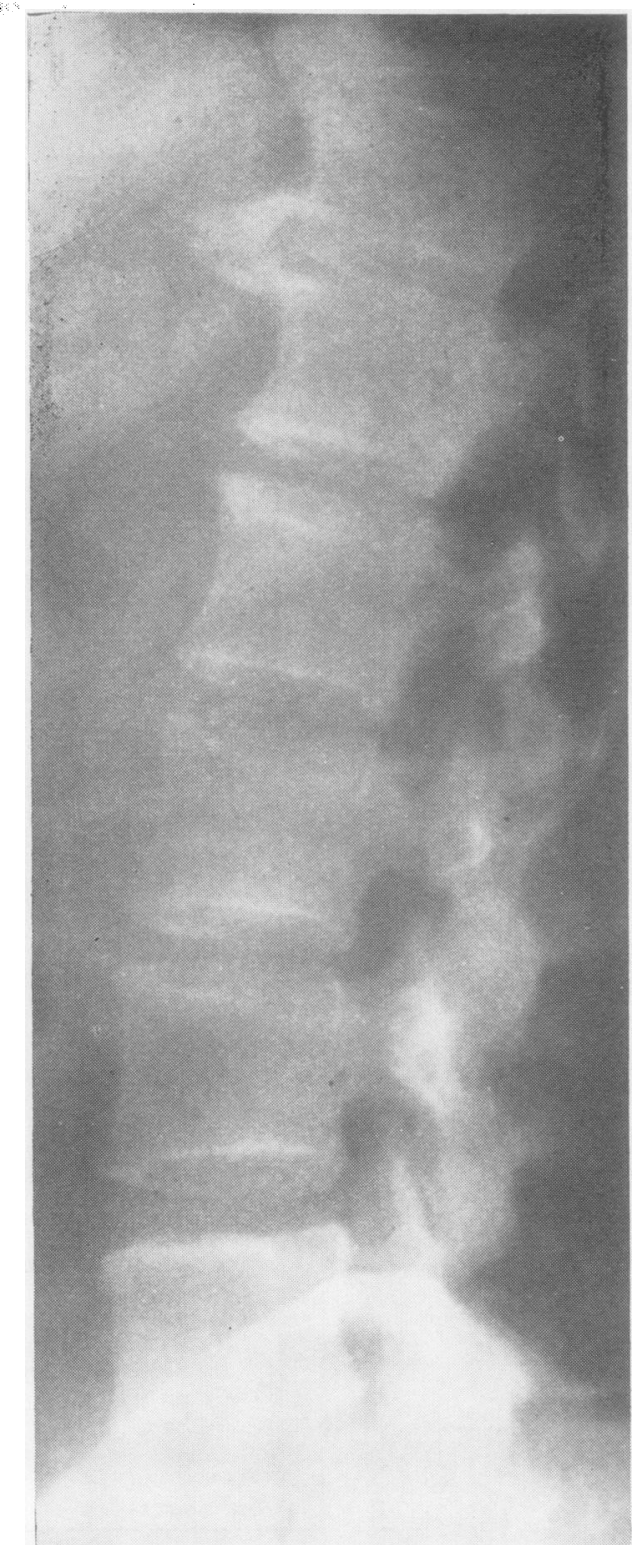

Fig. 5.-Lumbar and lower thoracic spine, Lateral view (Patient III, 10). Note giant osteophytes D11 and 12 and normal lumbar spine.

A second branch of the family, consisting of the first cousins of the original patient, was later seen. All members of this family who are in London have been examined except one young woman (IV, 8) who refused.

As can be seen from the family tree (Fig. 4), there are four first cousins in London. All four have tylosis and the elder two (III, 1 and 3 ) have AVH, their $x$ rays (Figs 7 and 8) being very similar to those of the affected members of the first branch of the family. All are overweight and two are grossly obese. Seven of the nine children of these patients have been seen; one (IV, 11) has tylosis, but no spinal changes have been demonstrated.

\section{Discussion}

Paravertebral calcification is a feature of a number of diseases. Thus it is commonly seen in ankylosing spondylitis and may occur when the spine is involved in psoriatic arthritis (Bywaters and Dixon, 1965; Jajić, 1968) or Reiter's disease (Ford, 1953; Romanus, 1953; Lefkovits and Thomas, 1958). Minor changes are often seen in simple degenerative disease of the spine (spondylarthrosis), and calcification is a feature of several metabolic and biochemical disturbances, such as ochronosis, fluorosis, idiopathic hypoparathyroidism (Salvesen and Böe, 1953, Gibberd, 1965), and hypophosphataemia or vitamin D resistant rickets (Blackard, Robinson, and White, 1962; Stanbury, Popert, and Ball, 1959). It occurs also in the rare heredofamilial vascular and articular calcification described by Sharp (1954).

In the condition described by Forestier and RotèsQuerol (1950) and called by them ankylosing hyperostosis of the spine, ligamentous ossification appears to start opposite to the disc space; this spreads in both directions, finally forming a continuous ribbon. Fig. 8 shows typical early changes in the cervical area and Figs 2, 3, and 7 show later stages in the disease. Very large osteophytes are often present and sclerosis around the sacroiliac joints is also common. The condition is clinically benign and apart from stiffness of the affected area of the spine many patients are asymptomatic, while others experience only mild to moderate backache.

In the family described, although eight members have $x$-ray changes, only three have backache. This is not severe, symptoms being easily controlled by simple analgesics. The $x$ rays show ossification in the paraspinal ligaments, most pronounced in the lower thoracic region where it occurs mainly on the side opposite to the aorta. Some large osteophytes are present, but there is no narrowing of the disc spaces or signs of inflammatory sacroiliac disease, although several members have some sclerosis around these joints. These changes are identical with those described in senile ankylosing hyperostosis and the combination of these $x$ rays with normal laboratory investigations and a very benign clinical picture make it probable that this is a similar condition to that described by Forestier. However, in contrast to previously described cases, the ages 


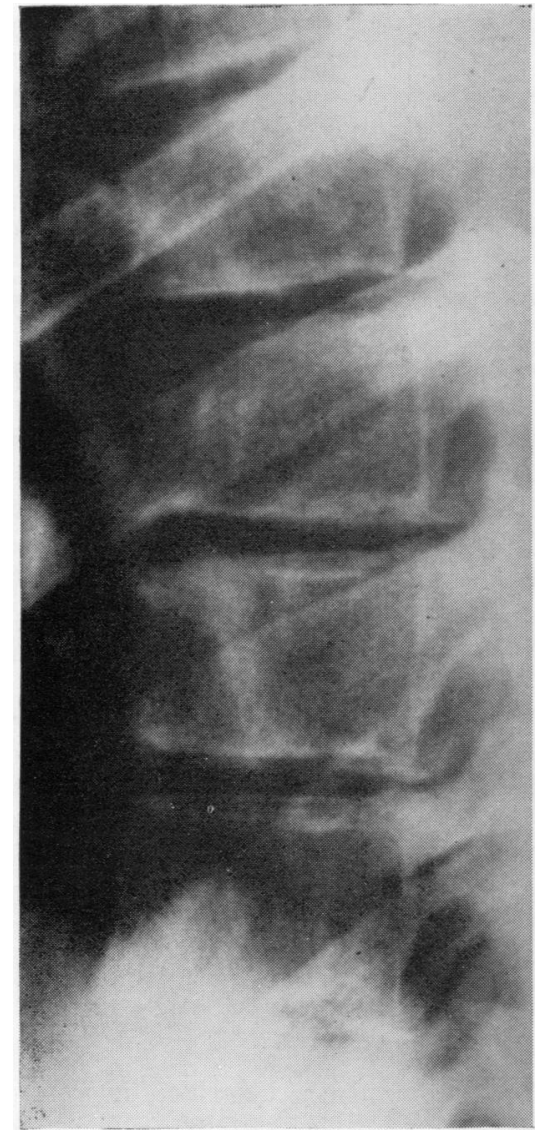

Fig. 6.-Early changes in the thoracic spine in a patient aged 18 (IV, 22).

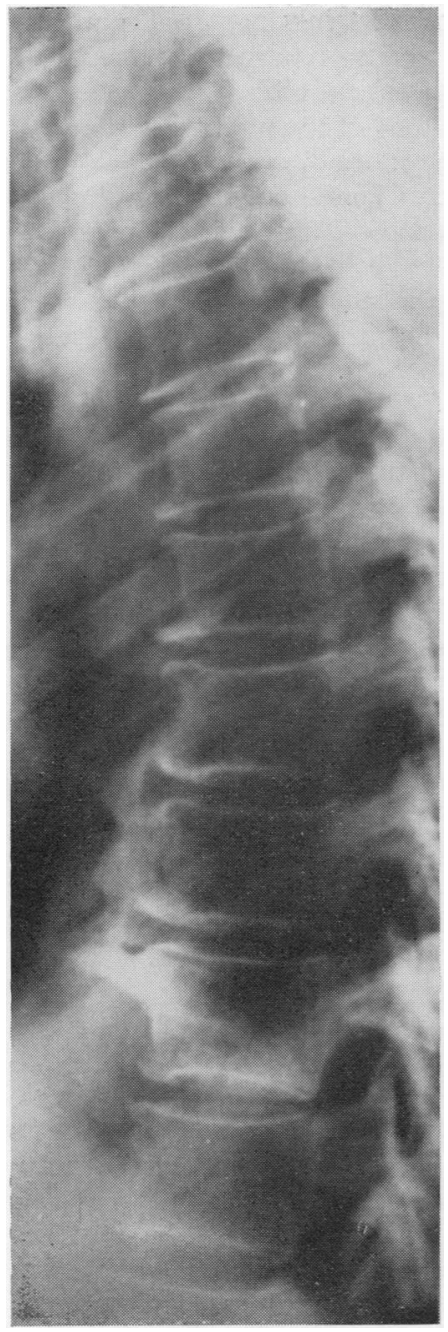

Fig. 7.-Thoracic spine, lateral view (Patient III, 1).

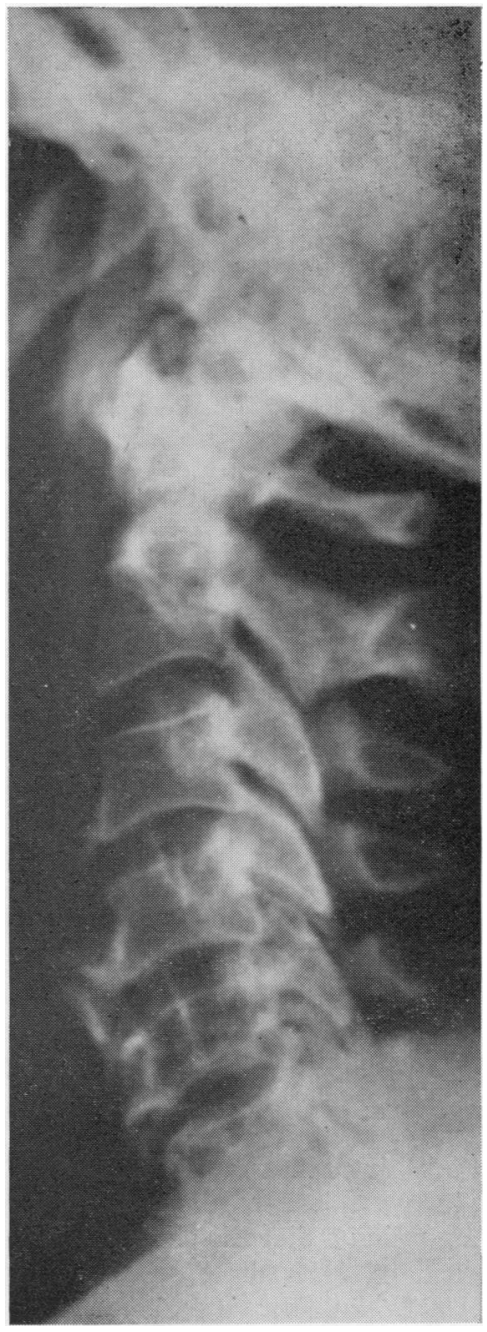

Fig. 8.-Cervical spine, lateral view (Patient III, 1). Note early ossification of anterior spinal ligament opposite disc space and osteophytes. of the patients described here (18 to 50 years) are much lower than those previously recorded. Thus, in the largest reported survey, from the Mayo Clinic (Smith, Pugh, and Polley, 1955), the average age was 65 years; other workers have also found the condition rare before the seventh decade (Forestier and Rotès-Querol, 1950; Ott, 1953).

Whether AVH is merely an exaggerated form of the normal degenerative changes affecting the spine as suggested by Ott (1953) and Smith and others (1955) or a disease in itself is difficult to say. Degenerative spinal disease (spondylarthrosis) is almost invariably accompanied by degenerative disc disease and changes are usually most marked in the lumbar and cervical areas of the spine. In AVH and in this particular family, there was no evidence of disc disease and changes were most marked in the thoracic spine. It seems unlikely therefore that AVH is a manifestation of spondylarthrosis.

Obesity is known to accelerate spondylarthrosis and it is possible that the familial obesity plays some part in the early development of AVH in this family. In this context it should be noted that the most severe $x$-ray changes are present in three grossly obese female patients (III, 1, 8, and 9). The younger brother, (III, 10) who has always controlled his weight and the older brother (III, 7) who dieted and has maintained a normal weight for 6 years have less severe $x$-ray changes. However, weight cannot be the only factor involved 
because minimal changes are almost certainly present in the 18-year-old boy (IV, 22)) who is of normal build. It is also of interest that the patient (III, 4) who has tylosis and is one of the fattest of them all (weight $280 \mathrm{lb}$., height $5 \mathrm{ft} 4 \mathrm{in}$.) has a normal spine.

While the presence of tylosis in this family could be coincidental, its existence in all those with spinal hyperostosis suggests that there may be a genetic link with the spinal changes. Tylosis is usually familial and many families have been described showing a simple autosomal dominant inheritance of this trait (Michael, 1933). This appears to be the mode of inheritance in the family described and the tylosis appears to be of the type that manifests itself between the ages of 5 and 15 years.

An association between tylosis and a second disease has previously been noted in two family studies. Hanhart (1947) described a Swiss family, members of which developed tylosis at the age of 15 and multiple lipomata in the early 20s. HowelEvans, McConnell, Clarke, and Sheppard (1958) described two English families (probably related) in whom tylosis developed in the late teens, a high proportion of these tylotic patients later developed carcinoma of the oesophagus. There do not appear to be any previous reports of an association between tylosis and spinal disease either in isolated cases or in affected families.

Extensive investigations have failed to reveal any biochemical or inflammatory cause for AVH, but an association has been observed with diabetes mellitus. Ott and others (1967) reported that 22 per cent. of their patients with AVH had frank diabetes mellitus and 33 per cent. had an abnormal glucose tolerance test. On studying the patients attending a diabetic clinic, they found that 43.8 per cent. of 105 radiologically examined diabetics had AVH. Julkunen (1967) confirmed these findings, noting that 21 per cent. of 122 diabetics over 60 years of age had AVH, whereas only 4 per cent. of a well-matched control group had these spinal changes.

Glucose tolerance tests have been carried out in the affected members of the family described and are all normal. It is possible that the obesity of many diabetics of late onset contributes more to the aetiology of AVH than the disorder of carbohydrate metabolism, and $x$-ray studies of the thoracic spine in an unrelated group of non-diabetic obese patients shows an increased incidence of severe degenerative changes and AVH in the thoracic spine (Beardwell, 1969).

Boulet, Serre, and Mirouze (1954) and Boulet and Mirouze (1954) felt that the increased incidence of AVH in diabetes might be due to a disturbance in pituitary function in these patients, leading to an excess of growth hormone which accelerates the growth of osteophytes to hyperostosis. In an attempt to test this theory Julkunen (1967) $x$-rayed the spines of 21 proven acromegalics; eight of these patients were over 50 and four of the eight had AVH. No member of the present family showed any evidence of acromegaly or other clinical evidence of endocrine dysfunction.

Clinically and radiologically the Greek-Cypriot family described appear to have AVH, and the high familial incidence and association with tylosis, a known inherited disorder, suggests a genetic cause for AVH in this family. It is possible that the strains on the spine produced by excessive obesity contribute to its appearance at an early age, in a family already genetically predisposed to this condition.

\section{Summary}

A Greek-Cypriot family is described in whom paravertebral ossification essentially similar in appearance to senile ankylosing hyperostosis was observed in eight members ranging in age from 18 to 50 years. Fifteen of the family also suffer from tylosis (hyperkeratosis punctata plantaris), and many are excessively obese. No abnormalities of carbohydrate metabolism or other endocrine disturbance were demonstrated. The existence of ankylosing vertebral hyperostosis as a separate entity from spondylarthrosis is suggested and its aetiology discussed.

\section{REFERENCES}

Beardwell, A. (1969). In preparation (The relationship between obesity, diabetes and ankylosing vertebral hyperostosis).

Blackard, W. G., Robinson, R. R., and White, J. E. (1962). New Engl. J. Med., 266, 899 (Familial hypophosphataemia. Report of a case, with observations regarding pathogenesis).

Boulet, P., and Mirouze, J. (1954). Ann. Méd., 55, 674 (Les ostéoses diabétique (ostéoporose et hyperostose)).

—, Serre, H., and Mirouze, J. (1954). Sem. Hôp. Paris, 30, 2392 (Le rachis diabétique).

Bywaters, E. G. L., and Dixon, A. St. J. (1965). Ann. rheum. Dis., 24, 313 (Paravertebral ossification in psoriatic arthritis).

Ford, D. K. (1953), Brit. J, vener. Dis., 29, 123 (Arthritis and venereal urethritis). 
Forestier, J., and Rotès-Querol, J. (1950). Ann. rheum. Dis., 9, 321 (Senile ankylosing hyperostosis of the spine).

Gibberd, F. B. (1965). Acta endocr. (Kbh.), 48, 23 (Idiopathic hypoparathyroidism with unusual bone changes and spastic paraplegia).

Hanhart, E. (1947). Dermatologica (Basel), 94, 286 (Neue Sonderformen von Keratosis palmoplantaris, u. a. eine regelmässig-dominante mit systematisierten Lipomen, ferner 2 einfachrezessive mit Schwachsinn und Z. T. mit Hornhautveränderungen des Auges (Ektodermalsyndrom).

Howel-Evans, W., McConnell, R. B., Clarke, C. A., and Sheppard, P. M. (1958). Quart. J. Med., 27, 413 (Carcinoma of the oesophagus with keratosis palmaris et plantaris (tylosis); a study of two families).

Jajíc, I. (1968). Ann. rheum. Dis., 27, 1 (Radiological changes in the sacro-iliac joints and spine of patients with psoriatic arthritis and psoriasis).

Julkunen, H. (1967). "Proc. 6th European Congress of Rheumatology" (In press) (Hyperostosis of the spine in diabetes mellitus, acromegaly and in a selected part of the population).

Lefkovits, A. M., and Thomas, J. R. (1958). Ann. intern. Med., 49, 89 (Rheumatoid spondylitis: manifestations and management).

Michael, J. C. (1933). Arch. Derm. Syph. (Chicago), 27, 78 (Keratoderma disseminatum palmaris et plantaris-its mode of inheritance).

Ott, V. R. (1953). Schweiz. med. Wschr., 83, 790 (Uber die Spondylosis hyperostotica).

- Perkovak, N., and Regehr, I. (1967). "Proc. 6th European Congress of Rheumatology" (In press) (Hyperostotic spondylosis and ankylosing spondylitis. Correlation with disorders of carbohydrate metabolism).

—, Schwenkenbecher, H., and Iser, H. (1963). Z. Rheumaforsch., 22, 278 (Die Spondylose bei Diabetes mellitus).

Romanus, R. (1953). Acta med. scand., 145, Suppl. 280, p. 177 (Pelvo-spondylitis ossificans in the male and genito-urinary infection; the aetiological significance of the latter and the nature of the disease based on a study of 117 male patients).

Salvesen, H. A., and Böe, J. (1953). Acta endocr. (Kbh.), 14, 214 (Idiopathic hypoparathyroidism; observations on two cases, one complicated by moniliasis and idiopathic steatorrhea and one with unusual degree of calcium deposition in bones).

Sharp, J. (1954). Ann. rheum. Dis., 13, 15 (Heredo-familial vascular and articular calcification). (1957). Brit. med. J., 1, 975 (Differential diagnosis of ankylosing spondylitis).

Smith, C. F., Pugh, D. G., and Polley, H. F. (1955). Amer. J. Roentgenol., 74, 1049 (Physiologic vertebral ligamentous calcification: ageing process).

Stanbury, S. W., Popert, A. J., and Ball, J. (1959). Ann. rheum. Dis., 18, 63 (Simulation of rheumatic disorders by metabolic bone diseases).

\section{L'hyperostose vertébrale ankylosante familiale avec tylose}

\section{RÉSUMÉ}

Une famille cypriote-grecque est décrite chez laquelle une ossification paravertébrale essentiellement identique en apparence à celle de l'hyperostose ankylosante sénile a été observée chez huit membres âgés de 18 à 50 ans. Quinze membres de la famille étaient aussi atteints de tylose (hyperkeratosis punctata plantaris), et plusieurs d'entre eux étaient excessivement obèses. Aucune anomalie du métabolisme des hydrocarbones ou d'autres troubles endocriniens n'a été démontré. L'existence de l'hyperostose vertébrale ankylosante comme une entité séparée de la spondylarthrose est suggérée et son étiologie discutée.

\section{Hiperostosis vertebral anquilosante con tilosis en miembros} de una sola familia

\section{SUMARIO}

Se describe una familia grecochipriota, en la cual se observó osificación paravertebral, esencialmente similar, en apariencia, a la hiperostosis anquilosante senil, en ocho miembros de entre 18 y 50 años de edad. Quince de la familia sufrían también de tilosis (hyperkeratosis punctata plantaris), y muchos eran excesivamente obesos. No se demostraron anormalidades de metabolismo de carbohidratos $\mathrm{ni}$ otras alteraciones endocrinas. Se sugiere la existencia de hiperostosis vertebral anquilosante como entidad separada de la espondilartrosis y se discute su etiología. 